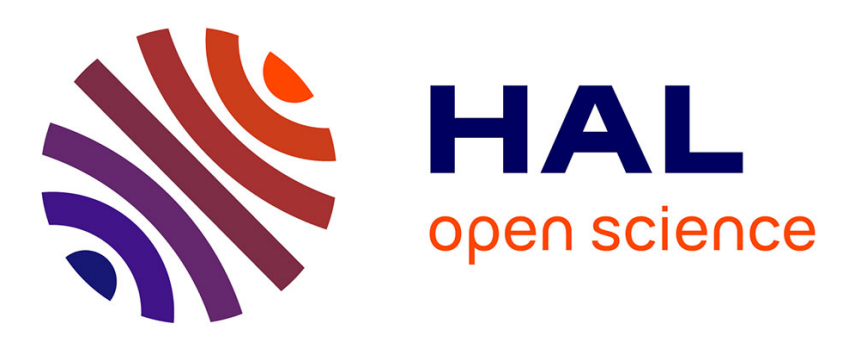

\title{
On line diagnosis of defaults on squirrel cage motors using FEM
}

Ammar Bentounsi, Alain Nicolas

\section{To cite this version:}

Ammar Bentounsi, Alain Nicolas. On line diagnosis of defaults on squirrel cage motors using FEM. IEEE Transactions on Magnetics, 1998, 34 (5 Part 1), pp.3511-3514. 10.1109/20.717828 . hal00141581

\section{HAL Id: hal-00141581 \\ https://hal.science/hal-00141581}

Submitted on 20 Apr 2007

HAL is a multi-disciplinary open access archive for the deposit and dissemination of scientific research documents, whether they are published or not. The documents may come from teaching and research institutions in France or abroad, or from public or private research centers.
L'archive ouverte pluridisciplinaire $\mathbf{H A L}$, est destinée au dépôt et à la diffusion de documents scientifiques de niveau recherche, publiés ou non, émanant des établissements d'enseignement et de recherche français ou étrangers, des laboratoires publics ou privés. 


\title{
On Line Diagnosis of Defaults on Squirrel Cage Motors Using FEM
}

\author{
A. Bentounsi \\ Institut d'Electronique de l'Universite de Constantine - Algerie \\ A. Nicolas \\ CEGELY - UPRESA CNRS 5005 -Ecole Centrale de Lyon - BP 163 - 69131 Ecully cedex - France.
}

\begin{abstract}
In industry, the predictive maintenance has become a strategic concept. Economic interest of on-line diagnosis of faults in electric machines gave rise to various researches in that field. This paper proposes a local approach to tackle the problem of breaking bars and end-rings of squirrel cage in induction machines based mainly on the signature of the local variables, such as the normal flux density. This allows a finer analysis, by use of a finite element based simulation.
\end{abstract}

Index terms-Induction motor, faulty cage, broken bars, diagnosis, finite element method, flux density.

\section{INTRODUCTION}

Statistics show that about $10 \%$ of induction motor breakdowns are located at rotor level and are in relative increase compared to the stator breakdowns due to the progress in insulation materials. This may come from a simple manufacturing defect (weak point at the bar ending join) or from a wear phenomenon accelerated by the internal constraints (electromagnetic, thermic, mechanic) or external constraints (over-load, frequent start ups,...).

Different methods for diagnosis have been developed. These are mainly based on the signature of the global external variables such as the stator current and torque. An analytical approach based on the rotating field theory and coupled circuit viewpoint is often used. Thus, we obtain a system of matrix equations which is transformed to a 2-axis model and solved by an implicit method.

This model has been developed in [1] but the restrictions imposed to the distribution of faults (broken bar) reduced the range of applicability of this method. However [2] proposed an analysis for any distribution and number of faults in a squirrel cage validated by the measurements of the rotor bar currents achieved on an experimental inverted-geometry motor. The phenomenon of the interbar current [3] flowing in the laminations is investigated by using FEM; this creates axial efforts. A transient model of cage induction machines in the rotor reference frame is developed in [4]. They show that the difference between the input currents of a machine having. a healthy and a faulty cage is significant when many broken bars are present

The problem of a reliable diagnosis (problem of cause separation) and precise diagnosis (detecting the first broken

Manuscript received November 3, 1997.

A.Nicolas, nicolas@trotek.ec-lyon.fr, http://www.cegely.ec-lyon.fr bar) is still open [5]. Thus, a thermic monitoring of the machine is proposed by [6]. This is a laborious and expensive method (due to important number of sensors).

In this paper, we present a local approach of diagnosis based on a numerical simulation of cage faults using the finite elements formulation. The interest of this method is the best understanding of the local phenomena (signature of local variables such as the flux density) and the simplicity of the detection (search coils).

\section{MOJJELS AND SOFTWARE}

When using the conventional finite element method, it is difficult to obtain the machine performances taking into account the eddy current, the external sources and the impedances. In order to tackle this problem, a new formulation is developed in [8]. It is a direct method which allows to solve simultaneously the coupled magnetic field and the electrical circuit equations. For the sake of simplicity, in the magnetodynamic problem, all variables are assumed to vary sinusoidally with time ( the differential operator $\partial / \partial \mathrm{t}$ is replaced by the factor $j \omega$ ) and the two-dimensional domain is considered ( the magnetic vector potential, $\mathbf{A}$, and the current density, $\mathbf{J}$, have only the axial $z$ components ). Thus, Maxwell's equations lead to

$$
\frac{\partial}{\partial x}\left(v \frac{\partial \mathbf{A}}{\partial x}\right)+\frac{\partial}{\partial y}\left(v \frac{\partial \mathbf{A}}{\partial y}\right)-j s \omega \sigma \mathbf{A}+\mathbf{J}=0
$$

where $v$ is the reluctivity of the materials, $\sigma$ is the conductivity of the conductors, $s$ is the slip and $\omega$ the angular frequency.

This formulation has been implemented in a CAD software, Flux 2D. We first modelled a low powered induction machine [7] using a complex magnetodynamic FEM coupled with the circuit equations. The results are quite satisfying for all the considered problems including magnetostatic, dynamic, linearity or non-linearity. However it is difficult to obtain a precise diagnosis in particular for weak slips. We have thus considered a $5 \mathrm{~kW}$ triphased tetrapolar induction machine (Fig. 1) with the particularity of being invertible for the needs of the experiments. The motor parameters are given in [9]. In the case of the healthy rotor cage, we have modelled only one fourth of the machine (Fig. 
2) under anti-cyclic conditions on the boundaries with the presence of "running band" in the air-gap. However, if there are no symmetry conditions (faulty cage), we have to consider the complete machine (Fig. 1a). In this case, the vector potential, A, is constant along the outside circumferential boundary (Dirichlet condition). The resolution was carried out in a magnetodynamic mode (steady-state sinusoidal) with coupling to a balanced triphased external source (Fig. 1b). Finally, the worse case was considered by fixing the slip of the motor at $1 \%$.

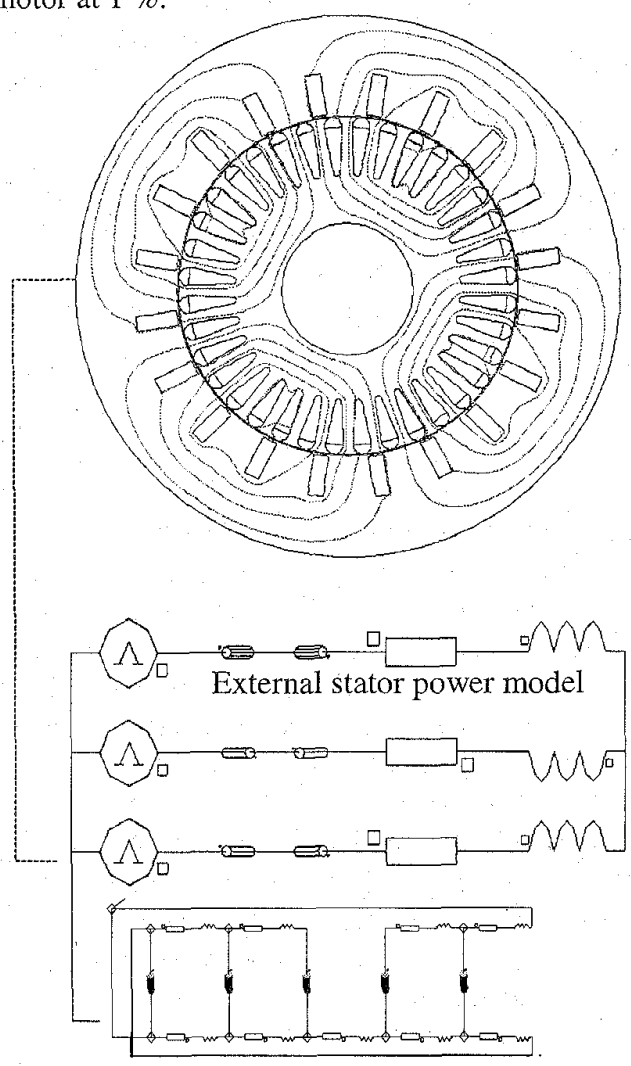

Electric rotor model

Fig. 1. Model of induction machine (a) flux lines of complete view (b) external source and rotor model

The above figure illustrates how the 3D and the external effects are taken into account :

the power source is a voltage one and the resistor and the inductance in the "stator" model describe the resistance and the inductance of the stator windings and especially the coil end leakage inductance. These can be either analitically evaluated or calculated using a 3D static package.

the rotor circuit model is made of as many short-circuited electrical circuits as bar numbers. The resistance and the inductance of these circuits take into account the end ring of the squirrel cage.

Such a model allows to describe a fault in the power circuit and also a fault in the cage : a broken bar means an infinite value of the serie resistance, a broken end ring means an infinite value of one of the end resistance, as explained below on figures 7 and 8 .

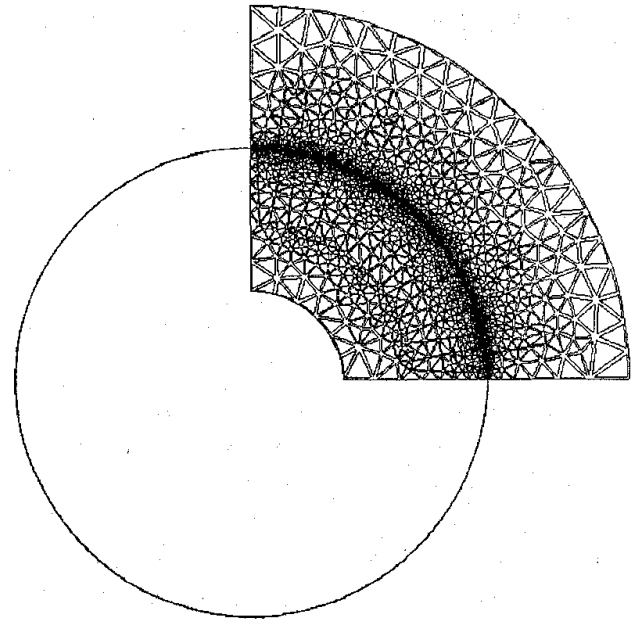

Fig. 2. Discretization of the one fourth geometry

III. SIMULATION AND TEST RESULTS

Such a model allows to simulate different kind of measurements to be made in order to detect a specific fault. After several investigations (position of a coil in the air-gap, components of the field to be measured), we can conclude that the local and typical signature of the failure is given by the normal component of magnetic flux density (Fig. 3).

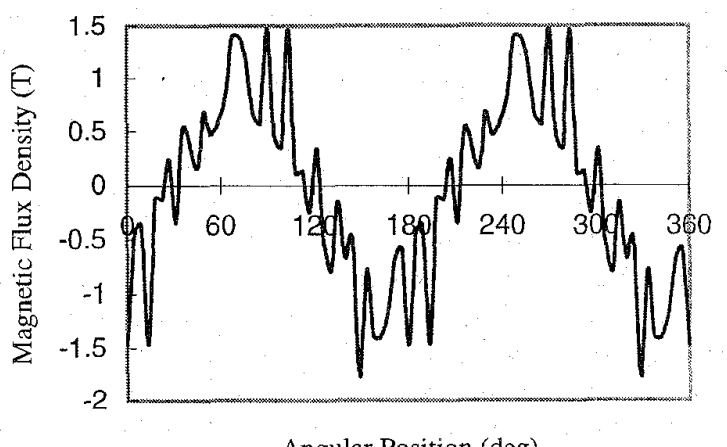

Fig. 3. Typical signature of a healthy cage such a signature will be the most distorted by one or more broken bars.

\section{A. Consequences of a broken bar}

To simulate the breaking of the bar number 2 for e.g., we allocate it either a quasi infinite resistivity or vacuum properties and we consequently modified the number of bars in the equivalent model of a squirrel cage. In both cases the results were similar.

1) At a local level: we observe a distorsion of the normal component of the flux density (Fig. 5a) due to a magnetizing 
and demagnetizing armature reaction on both sides of the defect as a result of the current distribution in the rotor bars given by the curve (Fig. 4).

2) At a global level: the well known results are a decrease of the torque for a given slip (the breaking of parallel bars is equivalent to an increase of the rotor resistor) and a modulation of the stator currents to a twice slip frequency .

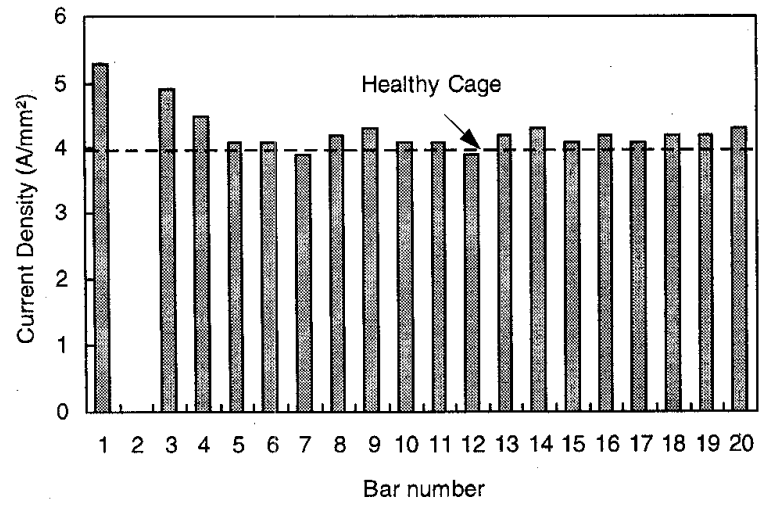

Fig. 4. Current density as a function of bar position

\section{B. Effect of the position and number of broken bars}

We have showed (Fig. 5) the displacement of the previously observed phenomenon with the position of the defect. The associed local distortion of the field oscillates at the slip frequency, $s(1$, with respect to the relative angular velocity of rotating field. Knowing that the relation between the angular displacement of the default, $\theta$, and the time, $t$, which is $\theta=(s \omega / \mathrm{p}) . \mathrm{t}$, we can represent (Fig.5) the moving displacement each $10 . \mathrm{T} ; \mathrm{p}$ is the number of pole pairs and $\mathrm{T}$ is the electrical period.

(a) Time to

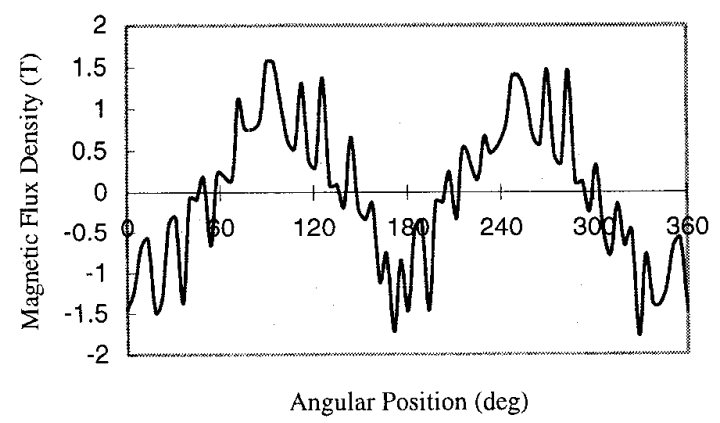

(b) Time $t_{1}=t_{0}+10 . T$

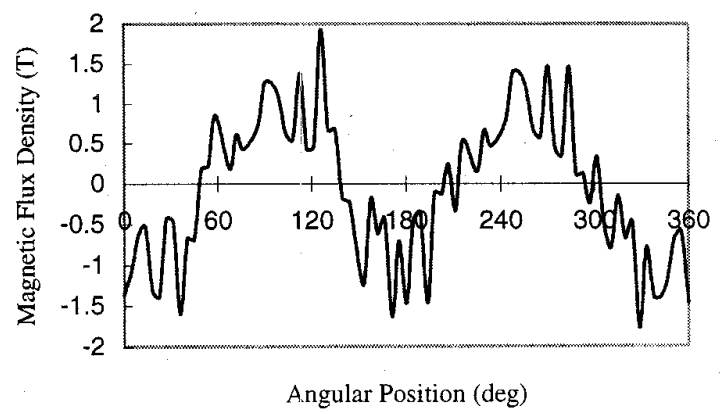

(c) Time $t_{2}=t_{0}+20 . T$

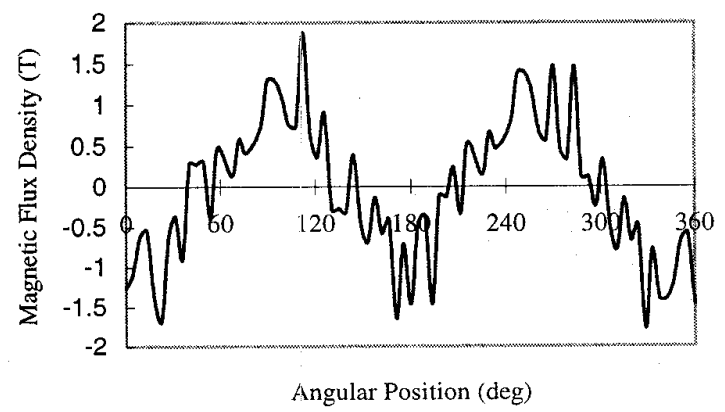

Fig. 5. Time displacernent of the local field perturbation

The signal processing to compare such a signature with the one of an healthy cage allows to get an accurate information, even with only one broken bar.. On the other side, the amplification of this distortion is directly related to the number of the broken bars (Fig. 6).

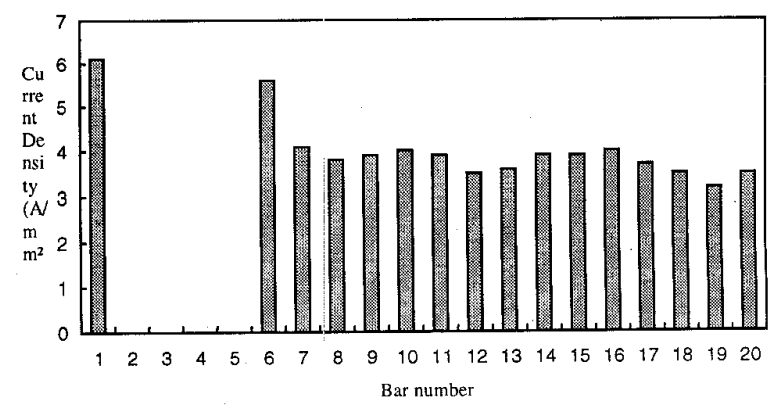

Fig. 6. Current density of four broken bars

\section{Effect of inter-bar current}

In order to study the effect of inter-bar current, we have used a model of the made of a multi-windings equivalent circuit (Fig. 7). The inter-bar current $I_{c}$ being a function of the ratio $R_{b} / R_{c}$ where $R_{b}$ is a bar resistor at low frequency and $R_{c}$ is a bar/end-ring contact resistor, we have only considered 
two extreme cases of a broken bar number 2 just at the side of the end-ring:

- when $R_{c}=1 \mathrm{~m} \Omega>R_{b}=10 \mu \Omega \Rightarrow I_{c}=0$ : we find again the case mentionned before;

- when $R_{c}=10 \mu \Omega=R_{b} \Rightarrow I_{c} \neq 0$ : we find the characteristics of a healty cage, but the presence of the interbars currents will create the axial efforts [3].

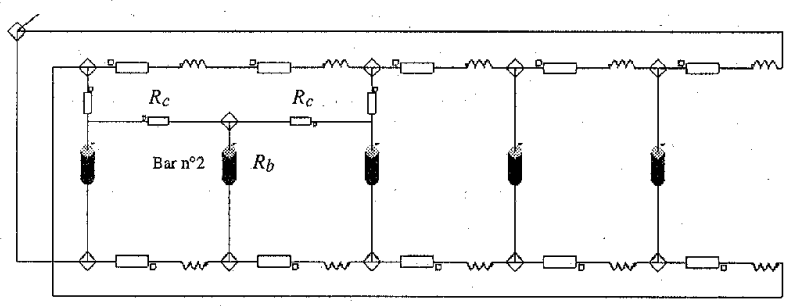

Fig. 7. Squirrel cage modelling inter-bar current

\section{Consequences of broken end-ring}

Using the squirrel cage model (Fig. 8a), we note that the effect of a broken end-ring corresponds to an increase of the normal flux density in the teeth located in front of the defect and to a decrease in the other side; this can be explained by an analysis of the spectral density (Fig. 8b) of the induced current. In that case, the characteristic distortion will also move with the displacement of the defect.

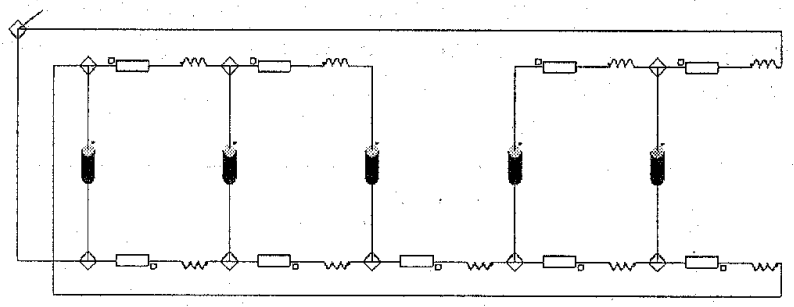

Fig. 8a. Squirrel cage modelling broken end-ring

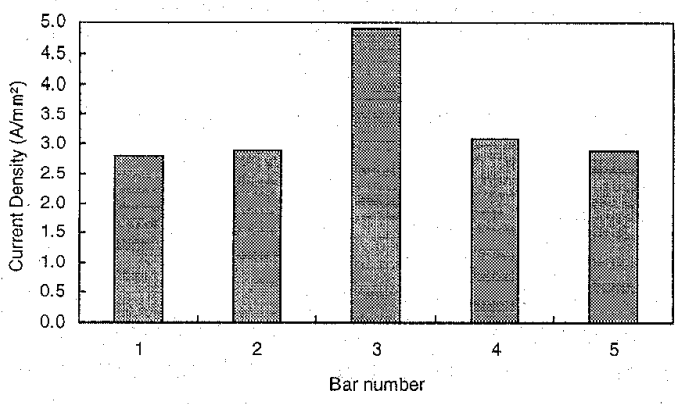

Fig. 8b. Current distribution in cage with a broken end-ring
The FEM analysis was also used to calculate the torqueslip characteristics of the induction motor under various fault conditions. The results allow to predict the degradation of the torque with respect to the number of broken bars.

\section{CONCLUSION}

The external approach based on the signature of the global and external variables such as the stator current and the torque is often used to tackle the problem of the cage faults in induction machines. But this method of detection is only significant if there are many broken bars. In this paper, we presented a local approach of on-line diagnosis by using the finite element formulation of the coupled problem implemented in a CAD software. This allows (i) a finer analysis (the signature of the defect is a distortion of the normal component of flux density which pulsates at a slip frequency), (ii) a better accuracy (detect the first default at a small slip) and (iii) a simpler mode of detection by analysing the frequency spectra of the emf induced in the search coils.

\section{ACKNOWLEDGMENT}

The computation presented in this paper has been performed using the Flux 2D software. The authors would like to thank Cedrat and Magsoft Corporation for their cooperation.

\section{REFERENCES}

[1] M. Jufer, A. Abdelażiz, "Influence d'une rupture de barre ou d'anneau sur les caractéristiques externes d'un moteur à cage", Bull. SEVNSE 69 (1978) 17, 9 Sept.

[2] S. Williamson, A. C. Smith, "Steady-state analysis of 3-phase cage motors with rotor bar and end-ring faults", IEE Proc., vol. $129, \mathrm{Pt}$. B n³, May 1982, pp. 93-100.

[3] G. H. Muller, C. F. Landy, "Finite element analysis of field distribution of squirrel cage induction motors having broken rotor bars and interbar currents", ICEM 94, Paris 5-8 Sept. 1994, pp. 577-581.

[4] P. Vas, F. Filippeti, G. Franceschini, C. Tassoni, "Transient modelling oriented to diagnostics of induction machines with rotor asymmetries" ICEM 94, Paris 5-8 Sept. 1994, t. 2, pp. 62-67

[5] G. B. Kliman, R. A. Koegl, "Non invasive detection of broken rotor bars in operating induction motors", IEEE Trans. on Energy Conv., vol. 3, no 4 , Dec. 1988 , pp. 873-879.

[6] D. J. Tilak, Siyambalapitiya, P. G. McLaren, P. P. Acarnley, "A rotor condition monitor for squirrel-cage induction machines", IEEE Trans. on Ind. Appl., vol. 23, n 2, March/April 1987, pp. 334-340.

[7] C. G. Hong, S. C. Ho, G. J. Hwang, "Characteristics of a squirrel cage induction motor", IEE Proc: $B$, vol. 138, $\mathrm{n}^{\circ} 3$, May 1991 .

18] P. Lombard, G. Meunier, "A general method for electric and magnetic coupled problem in 2D magnetodynamic domain", IEEE Trans. on Magnetics, vol. 28, $\mathrm{n}^{\circ}$ 2, March 92, pp 1291-1294.

[9] O. Sahraoui;"Calcul des schemas equivalents de la machine asynchrone par elements finis", Doctoral Thesis, Institut National Polytechnique de Grenoble, France, 1996 